\title{
The Effect of Aging Time on Mechanical and Microstructure Properties of Aa6061 Joints Welded by Gas Tungsten Arc Welding
}

\author{
R Ahmad* \\ Department of Manufacturing and Industrial Engineering, Faculty of Mechanical and Manufacturing Engineering, Universiti Tun Hussein Onn \\ Malaysia, Batu Pahat, Johor, Malaysia
}

Submitted:May 15, 2018; Published: May 23, 2018

*Corresponding author: R Ahmad, Department of Manufacturing and Industrial Engineering, Faculty of Mechanical and Manufacturing Engineering, Universiti Tun Hussein Onn Malaysia, 86400 Parit Raja, Batu Pahat, Johor, Malaysia, Tel: +6074564103; Email: roslee@uthm.edu.my

\begin{abstract}
This research examines the influence of heat treatment on mechanical properties and microstructure of AA6061 aluminium alloy welded with butt groove method, by using Gas Tungsten Arc Welding (GTAW) method. Welded samples were divided into two; heat treated (PWHT) and as-welded (AW) joints samples. For PWHT welded samples, the heat treatment applied were solution heat treatment at a temperature of 5300C for $1 \mathrm{~h}$, followed by cooling water and artificial aging process at a temperature of $1600 \mathrm{C}$ for 18,20 and 22 hours. Tensile test was performed based on standard ASTM E8 04, while the hardness test was taken at 3 different locations along the cross section of the weld zone of upper, middle and lower sections. Fracture surface at AW and PWHT welded samples were investigated by using Scanning Electron Microscopy (SEM) and the microstructure of the samples was analyzed by using Optical Microscopy (OM). From the results, the PWHT welded samples increased the tensile strength, hardness, and micro structural characteristics of welded joints aluminium AA6061 alloy.
\end{abstract}

Keywords: Heat Treatment; Welding; Aluminium Alloy; Microstructure; Mechanical Properties

\section{Introduction}

Welding is the primary joining method which has always represented a great challenge for designers and technologists. Many difficulties are associated with this kind of joint process, mainly related to the presence of a tenacious oxide layer, high thermal conductivity, and high coefficient of thermal expansion, solidification shrinkage, high solubility of hydrogen, and other gases in the molten state. Further problems occur when attention is focused on heat-treatable alloys, since heat provided by the welding process, is responsible for the decay of mechanical properties, due to phase transformations and softening [1]. AA6061 aluminium alloy (Al-Mg-Si alloys) is the most widely used medium strength aluminium alloy, and has gathered wide acceptance in the fabrication of light weight structures, good ductility, and good corrosion resistance [2]. The preferred welding processes for these alloys are frequently gas tungsten arc welding (GTAW) and metal inert gas (MIG) due to their comparatively easier applicability and better economy [3]. GTAW is an arc welding process that uses a no consumable tungsten electrode and inert shielding gases produces the highest quality welds of any open arc welding process [4]. TIG can be implemented with or without filler. Shielding was obtained from an externally supplied shielding gas. Welds are bright and shiny, with no slag or spatter, and require little or no post-weld cleaning [3]. Therefore, GTAW is easily used in all welding positions and provides excellent weld puddle control, especially on thin and intricate parts. Tungsten is a good electrode material due to its high melting point of $3410^{\circ} \mathrm{C}$. Typical shielding gases include argon, helium or a mixture of these gas elements [5]. The material of $6 \mathrm{xxx}$ class alloy can be heat treated to produce precipitation to various degrees [6]. According to Ozturk and Sisman [7], the T6 treatment involving solution heat treatment and the subsequence of artificial aging while quenching is a common method between solution heat treatment and precipitation treatment to increase the strength of alloy hardening of the alloys from this group is achieved due to precipitation of the phase MgSi occurring during aging. This phase has a fixed ratio between the elements contents, therefore amounts of magnesium and silicon in $6 \mathrm{xxx}$ alloys are balanced according to this ratio or with an excess of silicon [8]. From Tan and ÖGEL [9], the main components of heat treatable 6xxx series $\mathrm{Al}$ alloy are $\mathrm{Mg}$ and $\mathrm{Si}$, and 6xxx derives its strength from the precipitation hardening phase, $\mathrm{MgSi}$. The volume fraction of $\mathrm{MgSi}$ is affected primarily through the level of Mg within the alloy, but the Si content is also important [10]. 
Concluded that increasing Si in 6xxx type alloys increases strength in the T4 and T6 tempers. Another study on 6xxx carried out by Matsuda and Teguri [11] showed that the addition of copper to Al-Mg-Si alloys not only changes the precipitation sequence but also enhances hardness and refines microstructure. In solution treatment, the alloy is heated to within the solid solution phase and cooled rapidly, such as by quenching in water. The structure obtained soon after quenching, consists only if the single phase structure. This alloy has moderate strength and considerable ductility. TIG welding is a traditional technology for aluminium alloy welding. However, due to the high heat input in TIG welding, microstructure coarsening in the fusion zone of aluminium alloys would be formed associated with this welding process, which results in the obvious decrease of mechanical properties of the joints. However, it is essential that alloys are not heated above the solidus temperature which will cause overheating, i.e. liquation of compounds and grain boundary regions with a subsequent adverse effect on ductility and other mechanical properties. This process is applicable to the heat treatable alloys whereby the alloying constituents are taken into solution and retained by rapid quenching [12]. Subsequent heat treatment at lower temperatures is aging or naturally aging at room temperature allows for a controlled precipitation of the constituents thereby achieving increased hardness and strength [13]. Kou and Le [14] showed that the one of the reasons for the higher strength of the weld metal is the uniform distribution of precipitates in the matrix. This resulted in an improvement in hardness and enhanced the tensile properties of AA6061 joints.

The joints of post weld heat treated by solution treating at 5300C for 1 hour followed by artificial aging shows the reappearance of fine and grain boundary precipitates, where this precipitates dissolve during the solution treatment and are restored back by artificial aging. From Elangovan and Balasubramanian [15], the microstructure and the mechanical properties of an aluminium alloy will change after the welding because of the melting of the base material during the welding process. This contributes to its lack of strength. To overcome this problem, a heat treatment is performed to the welded part to obtain the desired mechanical properties and to relieve the residual stress on the part. The properties of various aluminium alloys can be altered by specifically designed heat treatments. Heat treatments for aluminium alloys are usually performed by solution heat treatments, followed by water quenching and aging at a certain temperature or by natural aging in air [16]. The artificial aging (precipitation strengthening) involving solution treatment at $550^{\circ} \mathrm{C}$, water quenching followed by tempering at $165^{\circ} \mathrm{C}$ for 10 hours results in effective dispersion of fine $\theta^{\prime}$ phase particles in the microstructure and was found to be the optimum precipitation strengthening parameters to render the material suitable for aerospace application [17]. Huda [17] concludes that the artificial ageing consists of further heating the casting at relatively low temperatures $\left(120-210^{\circ} \mathrm{C}\right)$ and it is during this stage that the precipitation of dissolved elements occurs. These precipitates are responsible for the strengthening of the material. In $\mathrm{Al} \mathrm{Si} \mathrm{Mg} \mathrm{alloys,} \mathrm{the} \mathrm{decomposition} \mathrm{of} \mathrm{the}$ supersaturated solution begins with the clustering of Si atoms. Most of the strengthening precipitates were dissolved during FSW and therefore, a much reduced density of precipitates was observed after welding. Solution heat treatment followed by aging formed a supersaturated solid solution, beginning the precipitation of strengthening particles in the matrix. The solution treated and aged precipitates are coarse and appear to be agglomerated continuously at the grain boundaries. Artificial aged joint, the precipitates are very fine and seem to be uniformly distributed throughout the matrix [18]. Menzemer and Lam [19] investigated the microstructures of TIG welded 5083 and 6061 aluminium alloy joints and found that microstructure coarsening was apparent in the fusion zone due to the slow dissipation of heat generated during welding. Lakshminarayanan and Balasubramanian [20] also found that coarse columnar grains were exhibited typically in the fusion zones of 6061 alloys, which resulted in a sharp decrease of joint strength compared to base metal. The size and distribution of MgSi precipitates play a major role in deciding the tensile properties and hardness of welds. From Huang and Kou [21], the micro structural analysis it is observed that the weld metals invariably consist of very fine grains. This is mainly due to the high solidification rates associated with GTAW. Fine evenly distributed MgSi precipitates are the reason for high strength AA6061 material. During welding, these precipitates are assumed to dissolve and the weld metal should be left devoid of any precipitates. However, due to the high cooling rates involved in welding not all of them get dissolved and few of them survive in a fine rounded precipitates [22]. Thus, the purpose of this study is to investigate the influence of PWHT on the mechanical and microstructure properties of Aluminium AA6061 alloy.

\section{Experimental Procedure}

The base materials used in the present study were $3 \mathrm{~mm}$ thick AA6061 aluminium alloy plates with chemical composition and mechanical properties listed in Table 1. As listed in Table 1 , the main elements such as $\mathrm{Mg}, \mathrm{Si}, \mathrm{Fe}$ and $\mathrm{Cu}$ in Aluminium alloy AA6061 lead to increase the mechanical properties [23] as tensile strength and elongation. The welding equipment was Gas Tungsten Arc Welding (GTAW) machine. GTAW process uses the heat produced by an electric arc created between nonconsumable tungsten electrodes and to produce the weld pool. ER 4043 is used as a filler material with a diameter of $1.2 \mathrm{~mm}$. Chemical compositions of the filler as well as welding parameter are shown in Tables $2 \& 3$. Figure 1 shows the complete welding specimen using GTAW process. Heat treatment processes involved in this experiment were solution heat treatment, water quenching, and artificial aging. 
Table 1: Chemical composition Mechanical properties and of AA6061 aluminium alloy.

\begin{tabular}{|c|c|c|c|c|c|c|c|c|c|c|c|}
\hline \multicolumn{9}{|c|}{ Chemical composition (wt.\%) } & \multicolumn{4}{|c|}{ Mechanical properties } \\
\hline $\mathbf{M g}$ & $\mathbf{S i}$ & $\mathbf{F e}$ & $\mathbf{C u}$ & $\mathbf{C r}$ & $\mathbf{M n}$ & $\mathbf{Z c}$ & $\mathbf{T i}$ & Al & $\begin{array}{c}\text { UTS } \\
\text { (Mpa) }\end{array}$ & $\begin{array}{c}\text { EL } \\
\text { (\%) }\end{array}$ & $\begin{array}{c}\text { Hardness } \\
\text { (VHN) }\end{array}$ \\
\hline 0.9 & 0.62 & 0.33 & 0.28 & 0.17 & 0.06 & 0.02 & 0.02 & Rest & 334 & 18 & 105 \\
\hline
\end{tabular}

Table 2: Chemical composition of filler (wt.\%)[24].

\begin{tabular}{|c|c|c|c|c|c|c|c|}
\hline $\mathbf{A l}$ & $\mathbf{S i}$ & $\mathbf{M g}$ & $\mathbf{C u}$ & $\mathbf{F e}$ & $\mathbf{M n}$ & $\mathbf{Z n}$ & $\mathbf{T i}$ \\
\hline 92.9 & 5.6 & 0.05 & 0.3 & 0.8 & 0.05 & 0.1 & 0.02 \\
\hline
\end{tabular}

Table 3: Welding parameter.

\begin{tabular}{|c|c|c|c|c|c|c|}
\hline Joint & Current (A) & Voltage (V) & Gas & $\begin{array}{c}\text { Heat Input } \\
\left(\mathbf{m m s}^{\mathbf{- 1}}\right)\end{array}$ & $\begin{array}{c}\text { Travel Speed } \\
\left(\mathbf{m m s}^{-1}\right)\end{array}$ & $\begin{array}{c}\text { Air Flow } \\
\left(\mathbf{L m i n}^{-\mathbf{1}}\right)\end{array}$ \\
\hline Double & 95 & 47 & Argon & 1.1 & 3 & 20 \\
\hline
\end{tabular}

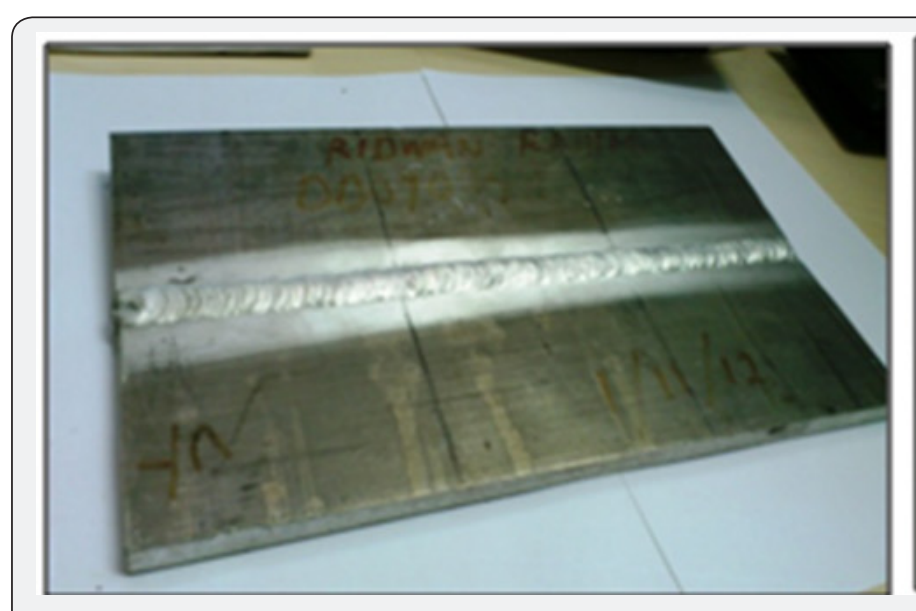

Figure 1: Complete welding specimen.

Solution heat treatment began when the samples were solutionized in the Carbolite HTF 1800 Furnace at the temperature of $530^{\circ} \mathrm{C}$ for 1 hour. Then, the samples were water quenched to prevent or retard immediate re-precipitation. The samples were age-hardened at temperatures of $160^{\circ} \mathrm{C}$ for 18 , 20 and 22 hours. In this experiment, in order to determine the performance of the sample as-welded and heat-treated, tensile and Vickers micro hardness tests were performed. Tensile experiment was carried out based on the standard ASTM E8 04 and the main focus was at the weld region of specimen for each AW and PWHT specimens. Tensile test was carried out with a $100 \mathrm{kN}$ and speed of $5 \mathrm{~mm} / \mathrm{min}$ using Universal Testing Machine. The hardness across the weld cross section was measured using Vickers micro hardness tester HMV SHIMADZU, following the standard ASTM E384-09. Microanalysis was used to investigate and analyzed the tensile fracture surfaces, microstructure and composition of the precipitate for as-welded and heat-treated samples. The Scanning Electron Microscopy (SEM) was used to study the failure pattern of as-welded and heat treatment

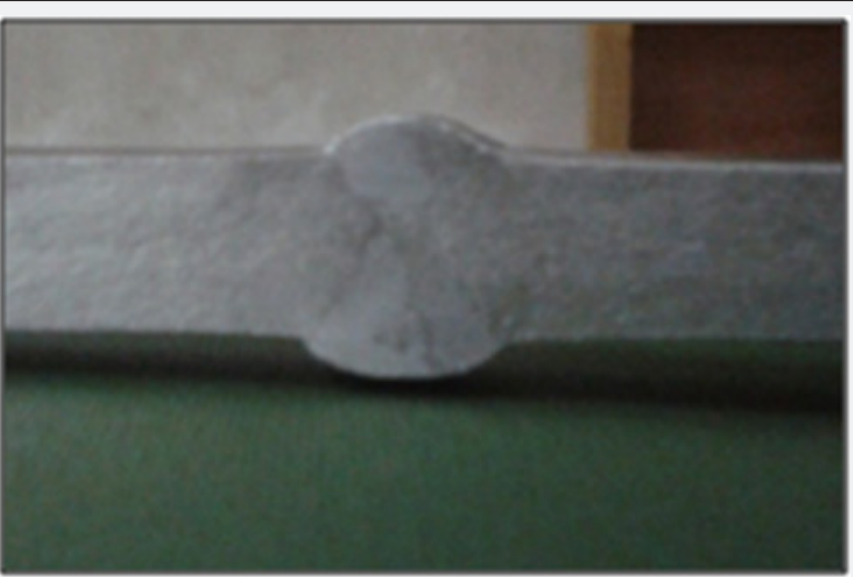

samples. The size and distribution of precipitates were analyzed using Olympus BX60M Optical Microscope (OM) at various locations in GTAW zone.

\section{Results and Discussion}

\section{Tensile Properties}

The transverse tensile properties of welded AA6061 joints are presented in Figure 2. The AW welded joint shows the lowest strength with $166.11 \mathrm{Mpa}$, meanwhile the strength of PWHT welded joint increased with increase the Aging time while, 22 hours was obtained highest strength $225.04 \mathrm{Mpa}$. As welded metal alloy (AW) shows an elongation of $3.86 \%$, while the reduction of elongation was obtained with increase Aging time, which PWHT for 22 hours was lowest elongation at 2.63\%. SEM micrographs were taken at three different locations, namely the top surfaces, the centre regions and at the bottom portions of the GTAW joints. The failure position of all joints during tensile tests was located in weld metal. 


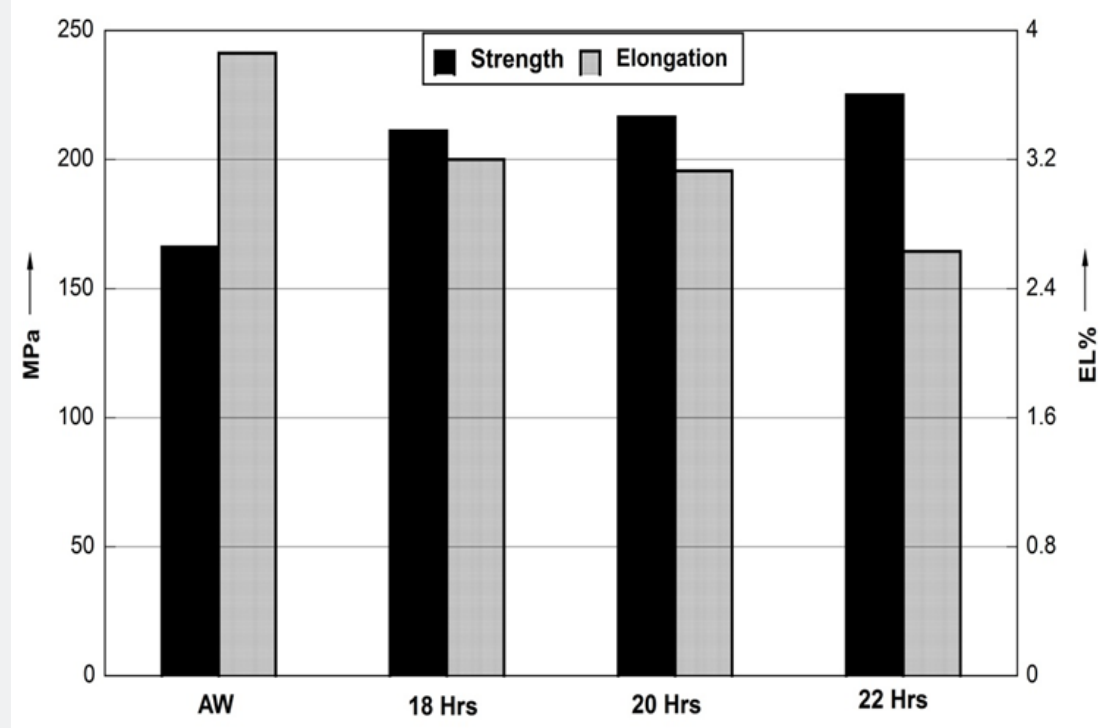

Figure 2: Tensile strength and Elongation of AW and PWHT welded joints.

\section{SEM Fractograph}

The fractured surfaces taken at the top surface of the tensile fractured surfaces are shown in Figure 3. All the fractured surfaces invariably consist of dimples, which is an indication that most of the failure is the result of brittle fractured. Fractured surface of AW joints in Figure 3(a) invariably show dimples and grain, which are larger than the PWHT joints. It can be seen from Figures 3b-3d that the fractured surface of PWHT joint invariably consists of finer and more-uniform dimples caused by increasing aging time, which reflects high in strength and low in ductile. Figure 4 shows the centre region of welded samples, where the dimples were larger compared to the top and bottom surfaces, in which the dimples were very fine. The reason for the welded material exhibits low quality of welding due to the centre is surrounded by heat affected zone (HAZ). For PWHT joints, the size of the grain and dimples were much smaller and finer, as the aging time was increased. From Figure 5, the grain size at the top and bottom was identically same and this is because of the double V-Groove joints. In the AW, the grains were large, and the distance between grains was high compared to the PWHT welded joint, where the grain size was constant, fairly small and the grains were located close to each other as the aging time was increased. The size and distribution of grains and dimples as well as the dislocation between the grains play a major role in the mechanical properties, such as tensile strength and hardness. As a consequence, higher tensile strength and hardness could be achieved for PWHT welded samples. From the experimental tensile result, it can be seen that the tensile properties of PWHT joints were much higher than AW joints and this is due to the solution and artificial aging treatment, which enhanced the tensile properties of the joints.
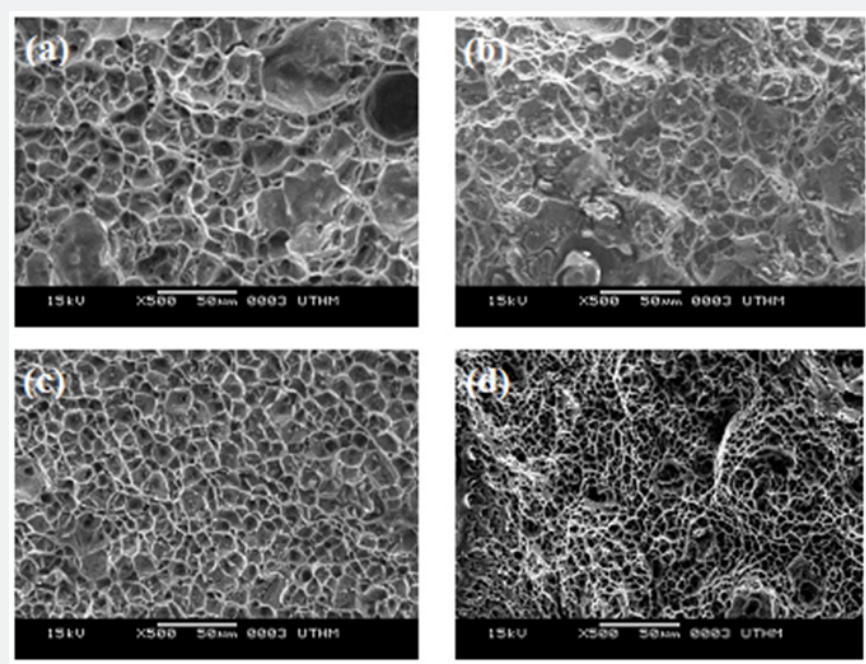

Figure 3: SEM fractured surfaces at the top surface (a) AW, (b) PWHT 18 Hours, (c) PWHT 20 Hours and (d) PWHT 22 Hours. 

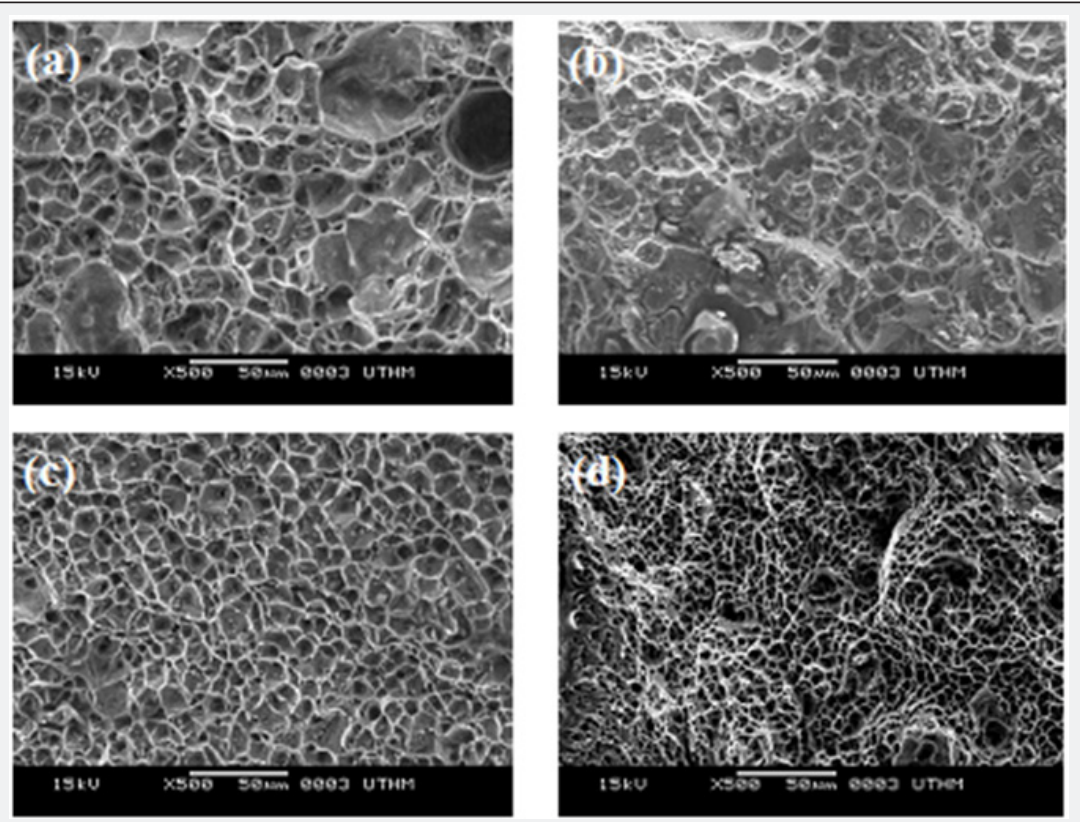

Figure 4: SEM fractured surfaces of the centre surface (a) AW, (b) PWHT 18 Hours, (c) PWHT 20 Hours and (d) PWHT 22 Hours.
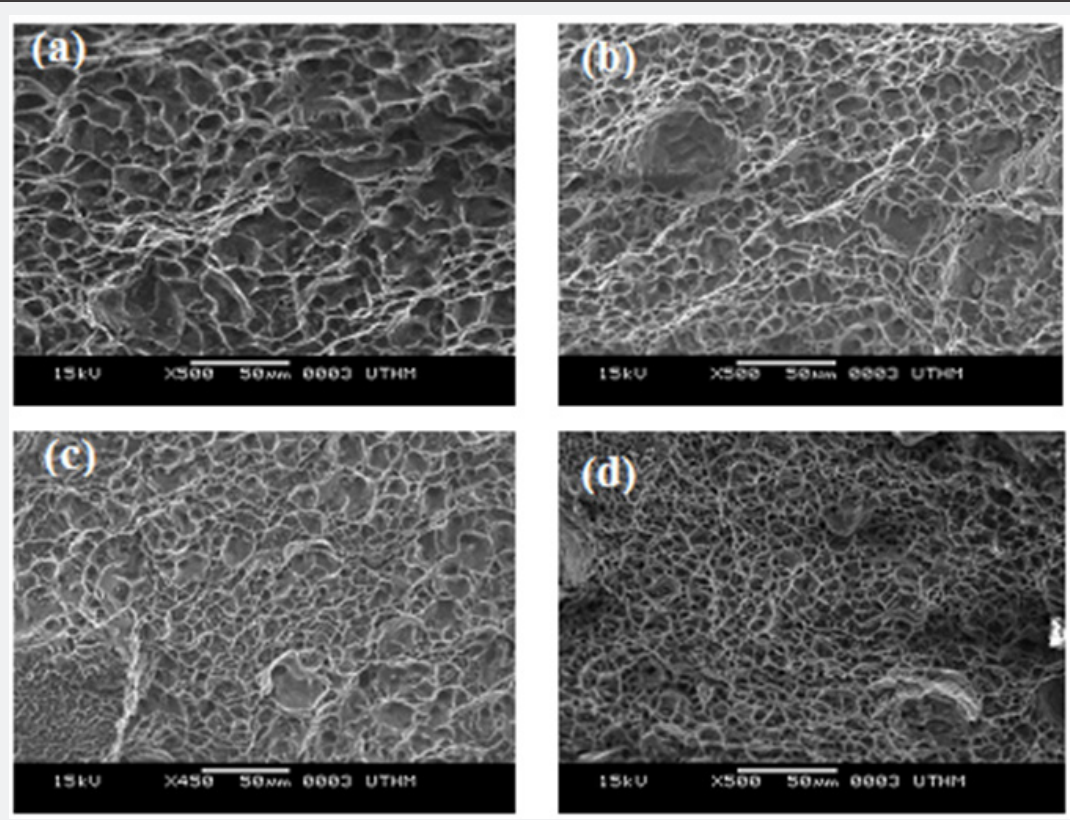

Figure 5: SEM fractured surfaces of the bottom surface (a) AW, (b) PWHT 18 Hours, (c) PWHT 20 Hours and (d) PWHT 22 Hours.

From the Figure 2, it is clear that the transverse tensile properties of AA6061 alloy were increased by the application of heat treatment process. Most of the tensile specimen failed at the weld region. Tensile fractured of PWHT joints were more granular and the fractured surface was covered with dimples of varying size and shape, which increased the locally brittle failure which may due to re-precipitation of Mg2Si that caused during aging process and dissolution of precipitates in matrix [24,25] . The width of the observed dimples under SEM in fractured surface of the heat treated joint was constant and fairly small, the grains were located close to each other and finer, compared to the as welded joint. The similar result was obtained by Krishnan [26] the improvement of tensile due also to refiner the grain. Therefore, the post weld heat treatments employed in this experiment helped to improve the tensile properties and hardness of the welded surface aluminium alloy.

\section{Hardness}

The hardness for post weld heat treated for 22 hours was 86.7 $\mathrm{Hv}$ at the top location, the hardness for as-welded alloy was $53.6 \mathrm{Hv}$ as showed in Figure 6(a), and the hardnesses for heat treated alloys for 18 and 20 hours were of $65.9 \mathrm{Hv}$ and $77.1 \mathrm{Hv}$ 
respectively. Figure 6(b) showed the harnesses for centre weld region for PWHT for 22, 20, and 18 Hours and AW were $85.9 \mathrm{~Hz}$, $75.3 \mathrm{Hv}, 65.6 \mathrm{Hv}$ and $52.4 \mathrm{Hv}$ respectively. The hardnesses for the last location at the end of weld cross-region presented in Figure 6(c), for PWHT for 22, 20, 18 hours and as welded were $86.2 \mathrm{Hv}$, $78.3 \mathrm{Hv}, 66.2 \mathrm{Hv}$ and $54.1 \mathrm{Hv}$ respectively. Based on the bar chart, the hardness at the top and bottom are identically the same for each welded joint. This is because of the double V-Groove joints. The hardness was significantly increased in the weld metal, irrespective of welding process, while the center of weld region shows a lowest hardness value. This is because the weld metal was surrounded by heat affected zone. From the scatter graph, it shows two points of lowest hardness which identified as the heat affected zone. Therefore, this is the area, where during tensile test, the specimen started to fail first because of the joint was strong enough. For the most PWHT specimens, the hardness is much greater than AW specimens. This is because the solution heat treatment, rapidly quenching and subsequently artificial aging were effective to increase the hardness value.

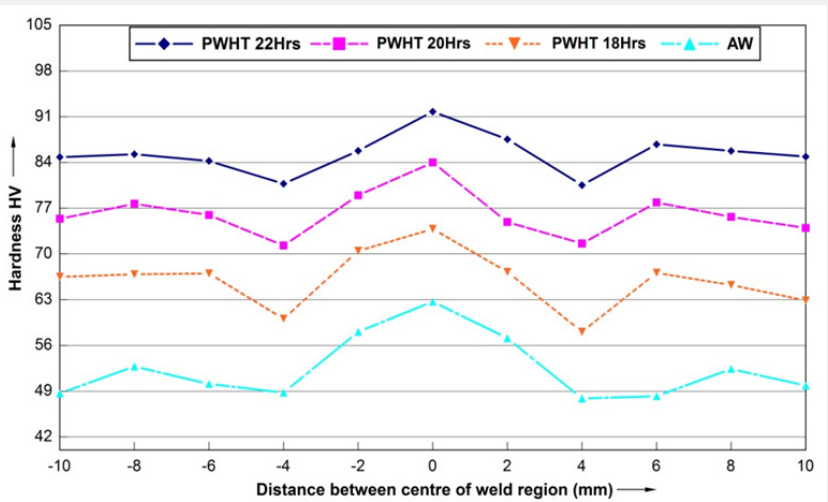

(a)

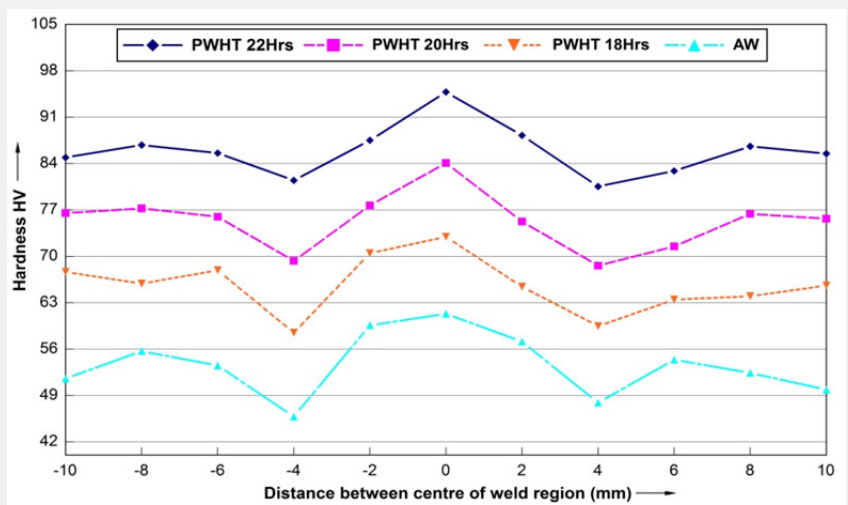

(b)

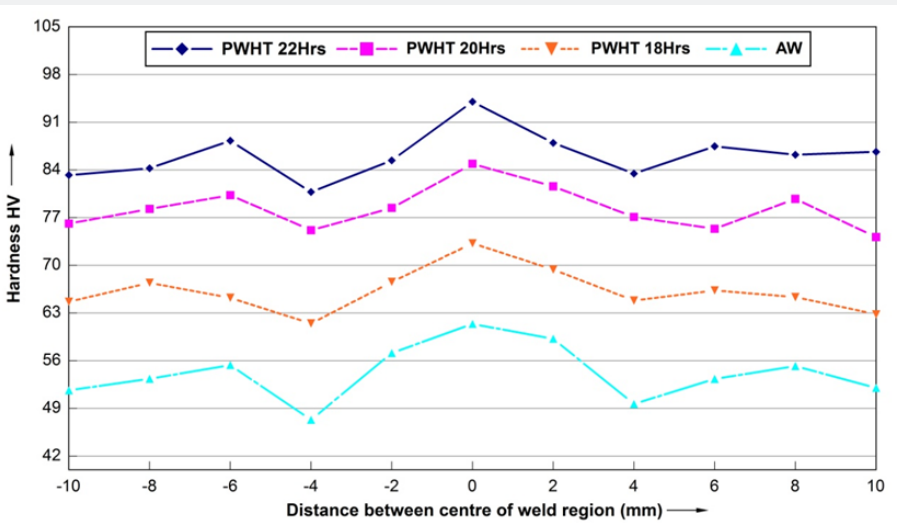

(c)

Figure 6: Hardness of weld region between AW and PWHT group at: (a) top, (b) centre, (c) bottom.

From the test, hardness value was taken at three different locations and the clear comparison can be seen where the hardness of PWHT welded sample shows a higher value compared to the as-welded specimen. Precipitation hardening, or age hardening, provides one of the most widely used mechanisms for the strengthening of metal alloys. The hardness in the precipitation hardening aluminium alloys greatly depends on the size and distribution of the hardening precipitates. The micro-hardness profile across the section of the weld zone of as welded and post weld heat treated alloys joint shows a general softening in the HAZ in contrast to the base metal (BM) and weld metal (WM). The Heat Affected Zone (HAZ) of the all alloy joint has a hardness value much lower than the hardness in base metal. The reason for this softening in the HAZ is the coarsening of hardening precipitates due to the solidification effect during the welding process $[2,27,28]$. On the other hand, a very fine grain structure allows a partial recovery in the weld metal or fusion zone, where the hardness value is greatly increasing up from the HAZ to fusion zone [29]. The major precipitate in 6000 series $\mathrm{Al}-\mathrm{Mg}-\mathrm{Si}$ alloy system is MgSi. The formation and distribution of these precipitates depend on solution and aging treatment.

\section{Microstructure and Metallography}

Micrographs taken at the base metal and welded region are shown in Figures $7 \& 8$. From the micrographs, it can be inferred that there is no alteration in grain size due to the various post-weld heat treatments used in this investigation. From the result of microstructure analysis, there is significant 
variation in size and distribution in strengthening particle. Secondly, finer and uniform distributed precipitates were seen in PWHT welded joints, compared to AW welded joints and the dislocation density was higher for PWHT joints compared to AW joints. Most of the strengthening precipitates present in the base metal were dissolved after joint welded. Therefore, a much-reduced density of precipitates was observed in Figures 7(a)-7(d). Solution treatment followed by artificial aging, the precipitate was very fine and seemed uniformly distributed at both PWHT welded region in Figures 7 \& 8. This phenomenon can be explained by the effect of artificial aging, the longer the specimen went through in the furnace, and the blacker particle appeared on the surface of the specimen. It is due to the fact that the main components of $6 \mathrm{xxx}$ series Aluminium alloy are Magnesium and Silicone, and $6 \mathrm{xxx}$ obtained its strength from the phase of precipitation hardening, MgSi $[9,25]$. This is the reason for the higher hardness and superior tensile properties of the post weld heat treatment of AA6061 alloy. The composition for the strengthening precipitates is determined by using EDS as shown in Figure 9. It was identified MgSi as a major precipitates in all joints. The increase in the distribution and size of the strengthening precipitates is shown in Figure 9, due to the increasing aging time 18, 20 and 22 hours. Similar result was obtained by Wang and Embury [30]. In addition the EDS indicate the presence of $\mathrm{Al}-\mathrm{Cu}$ phase which also have significant effect on mechanical properties [31].
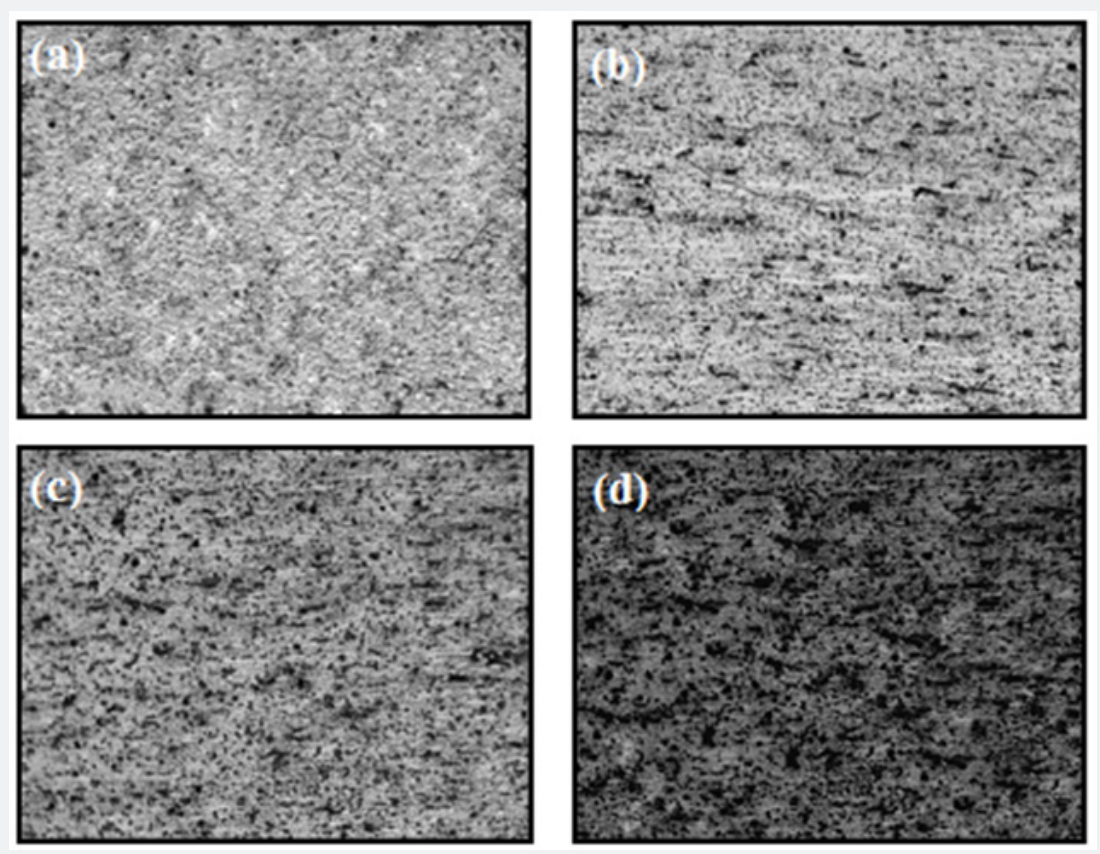

Figure 7: Microstructure of base metal region (a) AW, (b) PWHT 18 Hours, (c) PWHT 20 Hours and (d) PWHT 22 Hours.

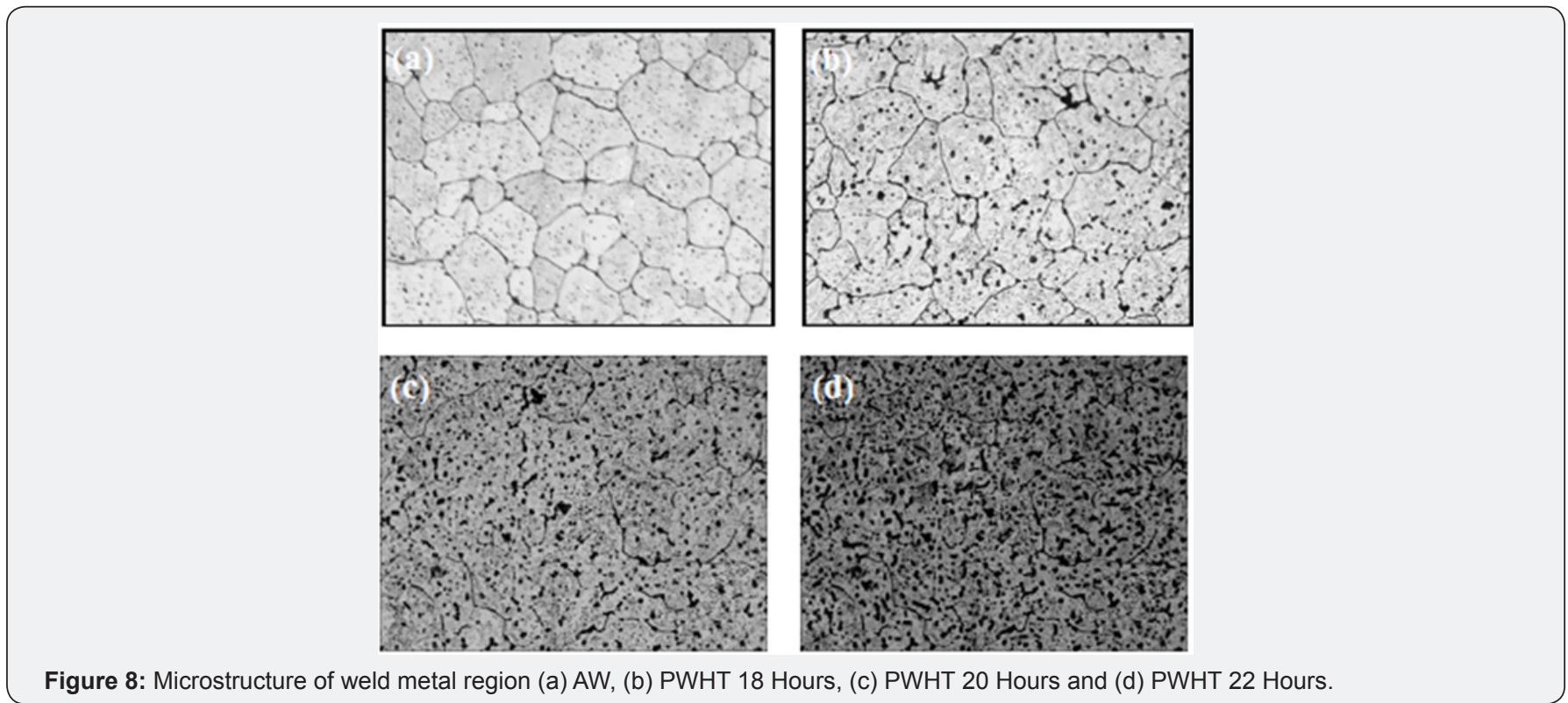




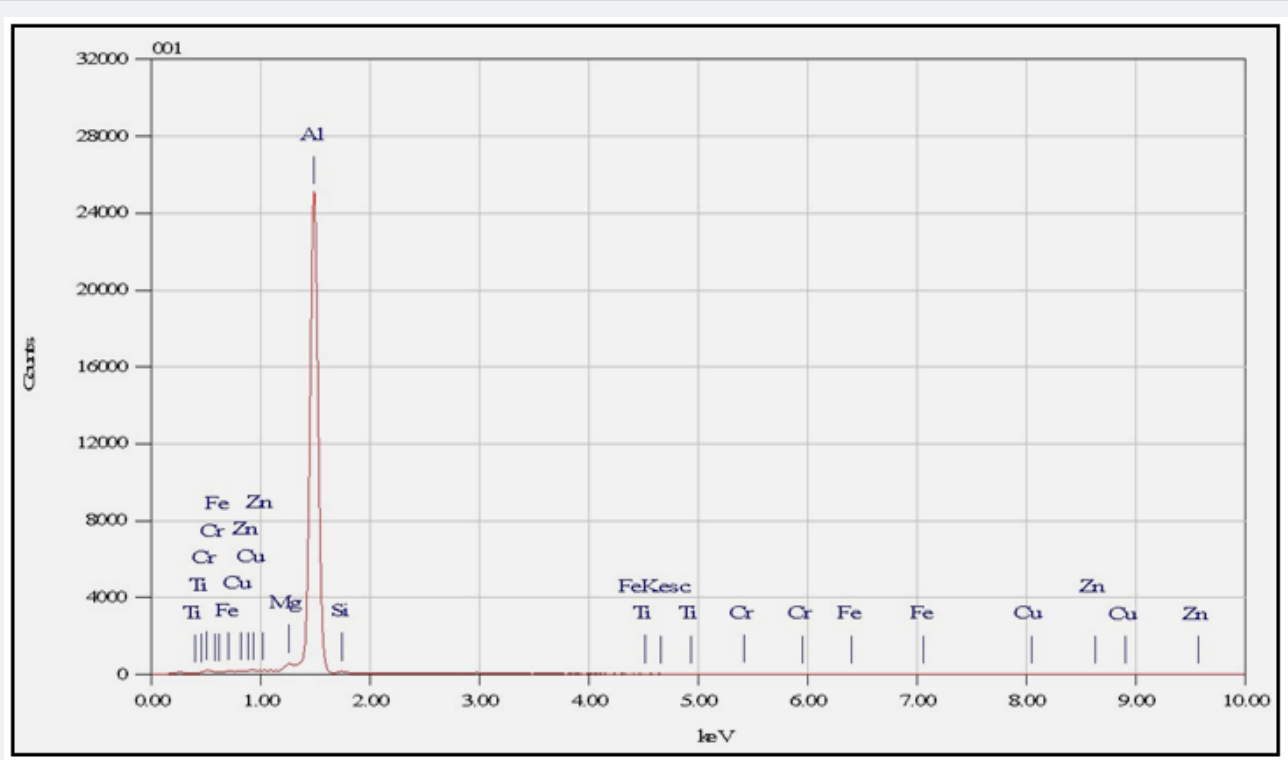

(a)

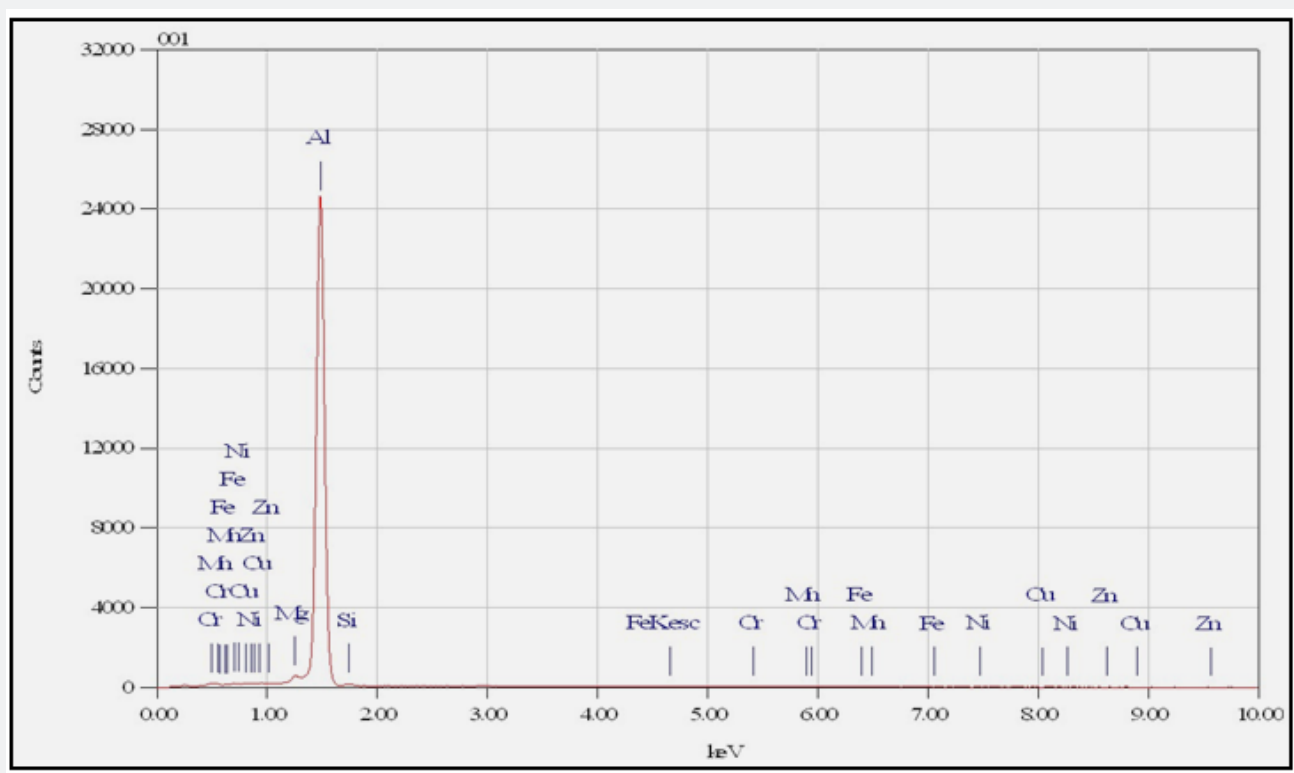

(b)

Figure 9: EDX composition analysis result (a) AW, (b) PWHT 22 Hours.

\section{Conclusion}

Heat treatment processes such as solution heat treatment at $530^{\circ} \mathrm{C}$ for 1 hour followed by water quenching and finally an artificial aging at $160^{\circ} \mathrm{C}$ for 18,20 and 22 hours have been investigated on structure and mechanical properties of AA6061 alloy. From the results, the mechanical properties such as tensile strength was improved by $35 \%$, when the gas tungsten arc welding joint was subjected to post-weld heat treatment with 22 hours artificial aging time. In addition, the micro-hardness was increased due to the PWHT contains fine and uniformly distributed hardening MgSi precipitates, which can be observed from microstructure analysis

\section{Reference}

1. Senthil Kumar, Balasubramanian, Sanavullah (2007) Influences of pulsed current tungsten inert gas welding parameters on the tensile properties of AA 6061 aluminium alloy. Mater Des 28(7): 2080-2092.

2. Ilangovan, Boopathy, Balasubramanian (2015) Effect of tool pin profile on microstructure and tensile properties of friction stir welded dissimilar AA 6061-AA 5086 aluminium alloy joints. Defence Technol 11(2): 174-184.

3. Mohandas, Madhusudan Reddy (1996) Effect of frequency of pulsing in gas tungsten arc welding on the microstructure and mechanical properties of titanium alloy welds: A technical note. J Mater Sci Lett 15(7): 626-628.

4. Reddy, Gokhale, Rao (1998) Optimisation of pulse frequency in pulsed current gas tungsten arc welding of aluminium-lithium alloy sheets. Mater Sci Technol 14: 61-66. 
5. Groover, Mikell (2007) Theory of Metal Machining. Fundamentals of Modern Manufacturing 3: 491-504.

6. Ahmad, Asmael (2015) Effect of aging time on microstructure and mechanical properties of AA6061 friction stir welding joints. Int J Automot Technol Mech Eng 11: 2364-2372.

7. Ozturk, Sisman, Toros, Kilic, Picu (2010) Influence of aging treatment on mechanical properties of 6061 aluminum alloy. Materials and design 31: 972-975.

8. Maisonnette, Suery, Nelias, Chaudet, Epicier (2011) Effects of heat treatments on the microstructure and mechanical properties of a 6061 aluminium alloy. Mater Sci Eng A 528(6): 2718-2724.

9. Tan, ÖGEL (2007) Influence of heat treatment on the mechanical properties of AA6066 alloy. Turk J Eng Environ. Sci 31(1): 53-60.

10. Hirth, Marshall, Court, Lloyd (2001) Effects of Si on the aging behaviour and formability of aluminium alloys based on AA6016. Mater Sci Eng 319: 452-456.

11. Matsuda, Teguri, Uetani, Sato, Ikeno (2002) Cu-segregation at the Q / $\alpha$ Al interface in Al-Mg-Si-Cu alloy. Scr Mater 47(9): 833-837.

12. Mrówka Nowotnik, Sieniawski (2005) Influence of heat treatment on the microstructure and mechanical properties of 6005 and 6082 aluminium alloys. J Mater Process Technol 162: 367-372.

13. Demir, Gündüz (2009) The effects of aging on machinability of 6061 aluminium alloy. Mater Des 30(5): 1480-1483.

14. Kou, Le (1986) Nucleation mechanism and grain refining of weld metal. Weld J 65: 65-70.

15. Elangovan, Balasubramanian (2008) Influences of post-weld heat treatment on tensile properties of friction stir-welded AA6061 aluminum alloy joints. Mater Charact 59(9): 1168-1177.

16. Sharma, Dwivedi, Kumar (2013) Effect of post weld heat treatments on microstructure and mechanical properties of friction stir welded joints of Al-Zn-Mg alloy AA7039. Mater Des 43: 134-143.

17. Huda (2009) Precipitation Strengthening and Age-Hardening in 2017 Aluminum Alloy for Aerospace Application. Eur J Sci Res 26: 558-564.

18. Sato, Arkom, Kokawa, Nelson, Steel (2008) Effect of microstructure on properties of friction stir welded Inconel Alloy 600. Mater Sci Eng A 477: 250-258.

19. Menzemer, Lamb, Srivatsan, Wittel (1999) An investigation of fusion zone microstructures of welded aluminum alloy joints. Mater Lett 41(4): 192-197.

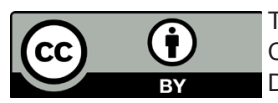

This work is licensed under Creative

Commons Attribution 4.0 Licens

DOI: 10.19080/JOJMS.2018.04.555646
20. Lakshminarayanan, Balasubramanian, Elangovan (2009) Effect of welding processes on tensile properties of AA6061 aluminium alloy joints. Int J Adv Manuf 40(3-4): 286-296.

21. Huang, Kou (2001) Partially Melted Zone in Aluminum Welds-Planar and Cellular Solidification. Weld J 80(2): 46-53.

22. Lin, Wang, Srivatsan (2003) A mechanism for the formation of equiaxed grains in welds of aluminum-lithium alloy 2090. Mater Sci Eng A 351(1-2): 304-309.

23. Davis (1993) Aluminum and aluminum alloys ASM international.

24. Ahmad, Bakar (2011) Effect of a post-weld heat treatment on the mechanical and microstructure properties of AA6061 joints welded by the gas metal arc welding cold metal transfer method. Mater Des 32(10): 5120-5126.

25. Sivaraj, Kanagarajan, Balasubramanian (2014) Effect of post weld heat treatment on tensile properties and microstructure characteristics of friction stir welded armour grade AA7075-T651 aluminium alloy. Defence Technol 10(1): 1-8.

26. Krishnan (2002) The effect of post weld heat treatment on the properties of 6061 friction stir welded joints. J Mater Sci 37(3): 473480.

27. Dong, Sun, Wang, Zhang, Li (2014) Microstructure, microhardness and corrosion susceptibility of friction stir welded AlMgSiCu alloy. Mater Des 54: 760-65.

28. Maamar, Mohamed, Rafik, Toufik, Nabil, et al. (2008) Heat treatment and welding effects on mechanical properties and microstructure evolution of 2024 and 7075 aluminium alloys. Mater Tehnol 42: 18.

29. Malin (1995) Study of metallurgical phenomena in the HAZ of 6061-T6 aluminum welded joints. Weld J 74: 305s.

30.Wang, Embury, Poole, Esmaeili, Lloyd (2003) Precipitation strengthening of the aluminum alloy AA6111. Metall Mater Trans A 34(12): 2913-2924.

31. Arunkumar, Rangarajan, Devakumaran, Sathiya (2015) Comparative study on transverse shrinkage, mechanical and metallurgical properties of AA2219 aluminium weld joints prepared by gas tungsten arc and gas metal arc welding processes. Defence Technol 11(3): 262-268.

Your next submission with Juniper Publishers
will reach you the below assets
- Quality Editorial service
- Swift Peer Review
- Reprints availability
- E-prints Service
- Manuscript Podcast for convenient understanding
- Global attainment for your research
- Manuscript accessibility in different formats
( Pdf, E-pub, Full Text, Audio)
- Unceasing customer service
Track the below URL for one-step submission
https://juniperpublishers.com/online-submission.php

